\title{
Ectopic pregnancy: a life-threatening gynecological emergency
}

This article was published in the following Dove Press journal:

International Journal of Women's Health

18 August 2013

Number of times this article has been viewed

\section{Osaheni L Lawani \\ Okechukwu B Anozie \\ Paul O Ezeonu \\ Department of Obstetrics and Gynecology, Federal Teaching \\ Hospital, Abakaliki, Nigeria}

Correspondence: Osaheni L Lawani Department of Obstetrics and Gynecology, Federal Teaching Hospital, Abakaliki, Ebonyi State, Nigeria

Tel +234803 669 I209

Tel +2347089009130

Email lawkins2000@yahoo.com
Background: Ectopic pregnancy is a life-threatening gynecological emergency, and a significant cause of maternal morbidity and mortality in Nigeria.

Objective: The aim of this work was to determine and evaluate the incidence, clinical presentation, risk factors, and management outcomes of ectopic pregnancies at Ebonyi State University Teaching Hospital (EBSUTH) in Abakaliki.

Methods: This was a retrospective, descriptive study of ectopic pregnancies managed in EBSUTH during the study period (June 1, 2002 to May 31, 2012). The medical records of the patients managed for ectopic pregnancy as well as the total birth record and gynecological admission records during the period under review were retrieved, and data were collected with the aid of data-entry forms designed for this purpose. There were 4,610 gynecological admissions and 9,828 deliveries, with 215 cases of ectopic pregnancies. A total of 205 cases were suitable for analysis after excluding cases with incomplete records. The relevant data collected were analyzed with SPSS version 15.0 for Windows.

Results: Ectopic pregnancy constituted $4.5 \%$ of all gynecological admissions, and its incidence was $2.1 \%$. The mean age of the patients was $27 \pm 2$ years, 196 of $205(95.6 \%)$ had ruptured ectopic pregnancies, and the remaining nine (4.4\%) were unruptured. The commonest (166 of $205,80.0 \%$ ) clinical presentation was abdominal pain, and the commonest ( 105 of 205, 51.2\%) identified risk factor was a previous history of induced abortion. Three deaths were recorded, giving a case-fatality rate of $1.4 \%$ (three of 205).

Conclusion: Ectopic pregnancy is a recognized cause of maternal morbidity and mortality and has remained a reproductive health challenge to Nigerian women, as well as a threat to efforts in achieving the UN's Millennium Development Goal 5 in sub-Saharan Africa.

Keywords: ectopic, emergency, pregnancy, sub-Saharan, life-threatening

\section{Introduction}

Ectopic pregnancy is a condition of immense gynecological importance, particularly in the developing world, because of the high morbidity and mortality associated with it and the enormous threat to life. When ruptured, ectopic pregnancy is a true medical emergency. It is the leading cause of maternal mortality in the first trimester and accounts for $10 \%-15 \%$ of all maternal deaths. ${ }^{1}$ Ectopic pregnancy is an important cause of maternal morbidity and mortality especially in developing countries, where the majority of patients present late with rupture and hemodynamic compromise. ${ }^{2}$ It is also a cause of fetal wastage and has been associated with recurrence and impairment of subsequent fertility. ${ }^{3}$

The true incidence of ectopic pregnancy is difficult to determine. ${ }^{3}$ It varies significantly among institutions and countries, depending on the denominator used in 
its calculations and the facilities available for diagnosis. Currently, the overall incidence is increasing worldwide, ${ }^{3-14}$ but the case-fatality rate has decreased. ${ }^{6,14}$ This might be due to a combination of increasing pelvic inflammatory disease (PID) and better antibiotics that permit tubal patency with luminal damage following infection, and an increase in ovulation induction, assisted reproductive technology, and improved diagnostic techniques. ${ }^{1,4,9}$ The reported incidence of this life-threatening condition varies from $0.67 \%$ in Western countries $^{3}$ to $0.9 \%-4.38 \%$ in Nigeria. ${ }^{15-23}$ In a previous study in this region (southeast Nigeria), an incidence of $1.98 \%$ was reported. ${ }^{24}$ More than $95 \%$ of ectopic pregnancies occur in the fallopian tube, making this the commonest site. ${ }^{1,4-6}$

The etiology of ectopic pregnancy is not well understood. ${ }^{1}$ However, multiple risk factors have been associated with ectopic pregnancy. Pelvic inflammatory disease, puerperal sepsis, postabortion sepsis, appendicitis, and the use of intrauterine contraceptive devices have been identified as sources of pelvic infection and major risk factors., ${ }^{3,4,6}$ Other etiological risk factors are tubal/pelvic surgeries, endometriosis, exposure to diethylstilbestrol in utero, chromosomally abnormal embryo, use of progesterone-only pills, cigarette smoking, conception following induction of ovulation and in vitro fertilization and embryo transfer (assisted reproductive technology), history of previous abortion, previous ectopic pregnancy, history of infertility, race, and age above 35 years. ${ }^{5,9}$ However, ectopic pregnancy can also occur without any obvious risk factors. , $^{5,25-28}$

Ectopic pregnancies could be asymptomatic, especially before rupture. When ruptured, symptoms could be acute or subacute. ${ }^{6}$ Since ectopic pregnancy is a major health problem among woman of reproductive age, the aim of this study was to determine the incidence and the clinical profile of patients presenting with ectopic pregnancy, as well as determine the risk factors, so as to make recommendations on interventions to reduce the incidence of this life-threatening condition in southeast Nigeria.

\section{Materials and methods}

This was a retrospective study of all cases of ectopic pregnancies admitted and managed at Ebonyi State University Teaching Hospital (EBSUTH) over a 10-year period (June 1, 2002 to May 31, 2012). EBSUTH was a state tertiary health facility in Abakaliki, Ebonyi State, Nigeria before its upgrade to the status of Federal Teaching Hospital in June 2012. It received referrals from all parts of the state and neighboring states of Nigeria. All cases of diagnosed ectopic pregnancy admitted through the accident and emergency unit as well as the gynecology clinic that were managed in the gynecological ward of EBSUTH were included in the study. The study was approved by the hospital's Research and Ethics Committee. The diagnosis of ectopic pregnancy was made mainly by history-taking, clinical physical examination, laboratory, and radiological (ultrasound) investigations. The medical records of all the patients admitted and managed for ectopic pregnancy during the study period were retrieved, and relevant data on age, parity, clinical presentation, risk factors, findings at laparotomy, and the outcome of treatment were collected using data-entry forms designed for this purpose. The gynecology and total birth records for the study period were also collected from the gynecology and labor ward record books. All those whose medical records were incomplete or missing were excluded from the study.

Statistical analysis was performed using SPSS version 15.0 for Windows (IBM, Armonk, NY, USA), and the process involved descriptive statistics.

\section{Results}

Over the 10-year study period, there were 4,610 gynecological admissions and 9,828 deliveries, with 215 cases of ectopic pregnancies, of which 205 cases were suitable for analysis. The incidence of ectopic pregnancy in this study was $2.1 \%$ (205 of 9,828), which constituted 4.5\% (205 of 4,610) of all gynecological admissions during the study period. The mean age of the patients was $27 \pm 3$ years, a total of $196(95.6 \%)$ had ruptured ectopic pregnancies, while nine (4.4\%) were unruptured. Table 1 depicts the biodemographic characteristics; the majority of patients $(90.7 \%)$ were within the age group 20-24 years. A significant proportion (67 of 205, 32.68\%) of these were nulliparous, while only six of 205 (2.93\%) were grand multiparous.

The clinical presentation is shown in Table 2. The commonest (166 of 205, 80.0\%) presentation was abdominal pain, 134 of 205 (65.4\%) had vaginal bleeding, 162 of 205 (79\%) presented with amenorrhea, 76 of 205 (37.1\%) presented with dizziness/fainting attack, and 21 of 205 (10.2\%) presented in shock. The majority of the patients (162 of 205 , $79 \%$ ) presented with amenorrhea (Table 2), 99.1\% of which was $\leq 12$ weeks (Table 3 ). The commonest site of ectopic gestation (Table 4) was the ampullary region of the fallopian tube (113 of $205,55.1 \%$ ), while the tubo-ovarian site had the lowest occurrence (five of 205, 2.4\%).

Table 4 shows that 79 of $162(45.9 \%)$ of ruptured ectopic pregnancies occurred at 8-12 weeks' gestation, and the majority of these occurred in the ampullary (57.6\%) followed by the isthmic (21.5\%) regions of the fallopian tube. 
Table I Biodemographic characteristics of patients with ectopic gestation

\begin{tabular}{lll}
\hline Age (years) & Number $(\mathbf{n}=\mathbf{2 0 5})$ & Percentage \\
\hline Less than 20 & 12 & 5.85 \\
$20-24$ & 72 & 35.12 \\
$25-29$ & 88 & 42.93 \\
$30-34$ & 26 & 12.68 \\
$35-39$ & 5 & 2.44 \\
40 and above & 2 & 0.98 \\
Parity & & \\
0 & 67 & 32.68 \\
I & 56 & 27.32 \\
2 & 48 & 23.41 \\
3 & 19 & 9.27 \\
4 & 9 & 4.39 \\
5 and above & 6 & 2.93 \\
Marital status & & \\
Married & 86 & 42.0 \\
Single & 119 & 58.0 \\
Occupation & & \\
Farmer & 20 & 9.76 \\
Hairdresser & 14 & 6.82 \\
Trader & 38 & 18.53 \\
Civil servant & 25 & 12.20 \\
Student & 88 & 42.93 \\
Housewife & 20 & 9.76 \\
\hline
\end{tabular}

All the ectopic pregnancies located in the interstitial/cornual region $(8.7 \%)$ of the fallopian tube ruptured at a gestational 8 weeks or more.

More than half (105 of 205, 51.2\%) had a past history of induced abortion, while 89 of 205 (43.4\%) had pelvic inflammatory disease, as risk factors for ectopic gestation (Table 5). Other associated risk factors were previous history of abdominopelvic surgery (8.8\%), puerperal sepsis (8.3\%), previous ectopic pregnancy $(3.4 \%)$, and use of intrauterine contraceptive devices (1\%).

The majority (196 of 205, 96.5\%) of the cases were diagnosed through history-taking, clinical physical examination, and abdominal paracentesis, while others had ultrasonography (120 of 205, 58.5\%), as depicted in Table 6 .

As shown in Table 7, 196 of 205 (95.6\%) of the patients had ruptured ectopic pregnancies, while nine of

Table 2 Clinical presentation of patients with ectopic pregnancy

\begin{tabular}{lll}
\hline Presentation & Number & Percentage \\
\hline Abdominal pain & 166 & 80.0 \\
Amenorrhea & 162 & 79.0 \\
Vaginal bleeding & 134 & 65.4 \\
Fainting attack/dizziness & 76 & 37.1 \\
Shock & 21 & 10.2 \\
Shoulder-tip pain & 17 & 8.3 \\
Diarrhea & 9 & 4.4 \\
\hline
\end{tabular}

Table 3 Duration of amenorrhea for both ruptured and unruptured ectopic pregnancies

\begin{tabular}{lll}
\hline Duration & Number & Percentage \\
\hline$\leq 7$ weeks & 86 & 53.2 \\
$8-12$ weeks & 74 & 45.9 \\
$\geq 12$ weeks & 2 & 0.9 \\
Total & 162 & 100 \\
\hline
\end{tabular}

Table 4 Site of ectopic pregnancy and gestational age at rupture

\begin{tabular}{|c|c|c|c|c|}
\hline & \multicolumn{3}{|c|}{ Number } & Percentage \\
\hline \multicolumn{5}{|c|}{ Site of both ruptured and unruptured } \\
\hline Ampulla & \multicolumn{2}{|c|}{113} & \multicolumn{2}{|c|}{55.1} \\
\hline Isthmus & \multicolumn{2}{|c|}{42} & \multicolumn{2}{|c|}{20.5} \\
\hline Fimbriae & \multicolumn{2}{|c|}{28} & \multicolumn{2}{|c|}{13.7} \\
\hline Interstitial/cornual & \multicolumn{2}{|c|}{17} & \multicolumn{2}{|c|}{8.3} \\
\hline Tubo-ovarian & \multicolumn{2}{|c|}{5} & \multicolumn{2}{|c|}{2.4} \\
\hline Total & \multicolumn{2}{|c|}{205} & \multicolumn{2}{|c|}{100} \\
\hline $\begin{array}{l}\text { Gestational age } \\
\text { (weeks) }\end{array}$ & $\begin{array}{l}\leq 7 \\
\text { n (\%) }\end{array}$ & $\begin{array}{l}8-12 \\
\text { n (\%) }\end{array}$ & $\begin{array}{l}\geq 12 \\
\text { n (\%) }\end{array}$ & $\begin{array}{l}\text { Total } \\
\text { n (\%) }\end{array}$ \\
\hline \multicolumn{5}{|c|}{ Gestational age at rupture for specific sites } \\
\hline \multicolumn{5}{|c|}{ Site of rupture } \\
\hline Fimbriae & $0(0)$ & $24(12.2)$ & $0(0)$ & $24(12.2)$ \\
\hline Ampulla & $43(21.9)$ & $68(34.7)$ & $2(1.0)$ & II $3(57.6)$ \\
\hline Isthmus & $42(21.5)$ & $0(0)$ & $0(0)$ & $42(21.5)$ \\
\hline Interstitial/cornual & $0(0)$ & $5(2.6)$ & $12(6.1)$ & $17(8.7)$ \\
\hline Total & $85(43.4)$ & $97(49.5)$ & $14(7.1)$ & $196(100)$ \\
\hline
\end{tabular}

Table 5 Risk factors found in patients with ectopic pregnancy

\begin{tabular}{lll}
\hline Risk factor & Number & Percentage \\
\hline Previous induced abortion & 105 & 51.2 \\
Pelvic inflammatory disease & 89 & 43.4 \\
Previous abdominopelvic surgery & 18 & 8.8 \\
Puerperal sepsis & 17 & 8.3 \\
Previous spontaneous abortion & 16 & 7.8 \\
Previous ectopic pregnancy & 7 & 3.4 \\
Intrauterine contraceptive device & 2 & 1.0 \\
\hline
\end{tabular}

Table 6 Diagnostic methods

\begin{tabular}{lllll}
\hline Method & Number & $\%$ & Positive (\%) & Negative (\%) \\
\hline \multicolumn{2}{l}{ Clinical/abdominal } \\
Paracentesis & 198 & 96.6 & $191(96.5)$ & $7(3.5 \%)$ \\
Pregnancy test & 121 & 59.02 & $95(78.5 \%)$ & $26(21.5 \%)$ \\
Ultrasound & 120 & 58.5 & $113(94.2 \%)$ & $7(5.8 \%)$ \\
Laparoscopy & 0 & 0 & 0 & 0 \\
\hline
\end{tabular}

Table 7 Operative findings

\begin{tabular}{lll}
\hline Findings & Number & Percentage \\
\hline Ruptured & 196 & 95.6 \\
Unruptured & 9 & 4.4 \\
Tubo-ovarian complex & 4 & 1.95 \\
Pelvic adhesions & 155 & 75.6 \\
\hline
\end{tabular}


Table 8 Type of surgical treatment

\begin{tabular}{lll}
\hline Surgery & Number & Percentage \\
\hline Salpingectomy & 178 & 86.8 \\
Salpingectomy and metroplasty & 19 & 9.3 \\
Salpingo-oophorectomy & 8 & 3.9 \\
Total & 205 & 100 \\
\hline
\end{tabular}

205 (4.4\%) were unruptured. Table 8 shows that the commonest surgical modality of treatment was salpingectomy (178 of $205,86.8 \%$ ); others were salpingectomy with metroplasty (19 of 205, 9.3\%) and oophorectomy (eight of 205, 3.9\%). The average packed-cell volume was $22 \% \pm 2 \%$ before surgery. Anemia was the commonest (122 of 205, 59.5\%) postoperative complication in this study (Table 9). All those who had anemia (122 of 205, 59.5\%) had severe anemia with packed-cell volume less than $21 \%$; they all received blood transfusion for this indication. Auto-blood transfusion was carried out intraoperatively using blood collected from the peritoneal cavity of those patients who had rupture ( 29 of 122, 23.8\%), while the others ( 93 of $122,76.2 \%$ ) were transfused for symptomatic postpartum anemia with blood sourced from the hospital blood bank. The case-fatality rate was $1.4 \%$ (three of 205); the deaths were from excessive hemorrhage from rupture of interstitial/cornual tubal ectopic pregnancies. Table 9 also shows a comparison between the frequencies of morbidity associated with both ruptured and unruptured ectopic pregnancies, indicating more morbidity with ruptures. The mean duration of hospital admission was $9 \pm 3$ days. Figure 1 depicts a rising trend of ectopic pregnancy during the study period.

\section{Discussion}

Ectopic pregnancy, especially when ruptured, is a lifethreatening gynecological emergency, more so in a resourceconstrained setting like Nigeria that has very poor maternal health indexes. The incidence of ectopic pregnancy found in our center during the study period was $2.1 \%$; this was consistent with the $2.31 \%$ reported in Benin, Nigeria. ${ }^{25}$ It was, however, higher than the $1.2 \%$ and $1.02 \%$ reported in

Table 9 Postoperative morbidity associated with ruptured and unruptured ectopic pregnancy

\begin{tabular}{lll}
\hline Morbidity & Ruptured, n (\%) & Unruptured, n (\%) \\
\hline Anemia & $122(59.5)$ & $0(0)$ \\
Fever/pyrexia & $50(24.4)$ & $7(3.4)$ \\
Wound sepsis & $21(10.24)$ & $0(0)$ \\
Urinary tract infection & $2(1.0)$ & $0(0)$ \\
Maternal death & $3(1.5)$ & $0(0)$ \\
Total & 198 & 7 \\
\hline
\end{tabular}

Ife and Ilorin ${ }^{15,20}$ respectively. The incidence in this study was higher than the $1.98 \%$ from a previous study in Abakaliki in $2003^{24}$; this goes to confirm the rising incidence of ectopic pregnancy in our environment and the world over. ${ }^{8-14}$

Ectopic pregnancy accounted for $4.5 \%$ of all gynecological admissions in our center during the study period. The high rate of ruptured ectopic pregnancies found in this study goes a long way also to buttress the fact that most people living in developing countries like Nigeria are yet to change their poor health-seeking behaviors in terms of accessing medical care early so that prompt diagnosis and treatment can be administered. ${ }^{26}$

The incidence of ectopic pregnancy was found to be highest in the 20-24-year age group. This was not surprising, considering that this is the reproductive age group and high risky sexual behavior is common in this age group. ${ }^{28}$ The highest incidence of ectopic pregnancy was noted amongst nulliparous women, which was in conformity with findings from some other Nigerian health institutions, where low parity was found to constitute a high-risk group. ${ }^{8,27}$ This may be because most young unmarried people with unintended pregnancies often procure unsafe abortions, which subsequently predisposes them to having an ectopic gestation in future pregnancies. A previous history of induced abortion and pelvic inflammatory disease were major risk factors in our subjects. This could be related to the risky sexual behavior common in this part of the world, as well as sepsis following backstreet abortions, as abortion in Nigeria is illegal and mostly clandestine. The increased risk of ectopic pregnancy in developed countries, just as recorded in this study, has been attributed to the following factors: pelvic inflammatory disease, smoking in women of reproductive age, increased use of assisted reproductive technology and increased awareness of ectopic pregnancy and its clinical presentation, facilitated by the development of specialized early pregnancy units. ${ }^{29}$

Early and accurate detection of ectopic pregnancy is critical to decrease morbidity and mortality and reduce costs associated with repeated emergency department visits, hospitalization, emergency and radical surgery, and future infertility evaluation and treatment. ${ }^{7}$ Lower abdominal pain was the commonest clinical presentation in our subjects, and this is often secondary to rupture due to late diagnosis and presentation. Other clinical presentations included amenorrhea, vaginal bleeding, dizziness/fainting attack, shock, shoulder-tip pain, and diarrhea. These occurred as a result of complications associated with ruptured ectopic gestation, and could be life-threatening without timely and effective 


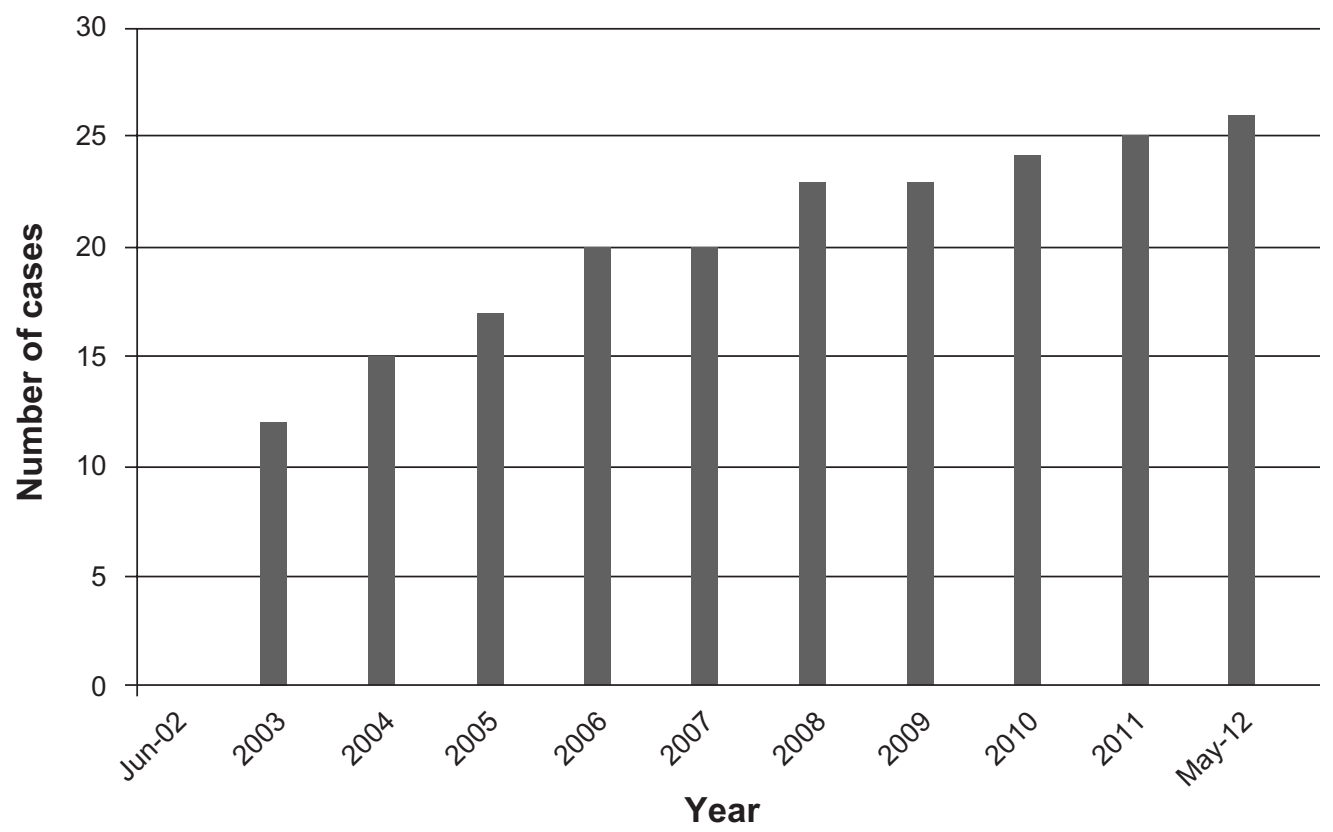

Figure I The trend of ectopic pregnancy over the study period.

interventions. This confirms the uniformity of the clinical presentation of ectopic pregnancy worldwide..$^{20,23}$

Patients with ruptured ectopic pregnancy could present with signs of shock, including hypotension, tachycardia, and rebound tenderness, and as such they should be treated on an emergency basis. ${ }^{30}$ In this study, the majority of the patients had ruptured ectopic pregnancy that was either acute or subacute, and our diagnosis was mainly based on history, physical examination, and abdominal paracentesis. Pregnancy tests were used as supportive diagnostic investigations, with diagnosis confirmed by transabdominal ultrasound scan. Ultrasound is useful in evaluating patients with suspected ectopic pregnancy, ${ }^{7}$ mainly by documenting the presence or absence of an intrauterine pregnancy at a discriminatory zone of about $6,500 \mathrm{mIU} / \mathrm{mL}$ of beta human chorionic gonadotropin ( $\beta$-hCG). ${ }^{1,3,31}$ The use of discriminatory zones as a diagnostic tool was not used in the study center, due to the challenge of getting a serum $\beta$-hCG done.

The commonest site of ectopic pregnancy from our findings was the ampullary region of the fallopian tube, which has also been reported as the commonest site by other studies. ${ }^{15,25,31}$ Due to the fact that many ectopic pregnancies resolve spontaneously, some cases of asymptomatic ectopic pregnancies in compliant patients can be managed expectantly if the $\beta$-hCG titer is low $(<200 \mathrm{mIU} / \mathrm{mL}){ }^{1,5,6}$ None of the patients in this study had expectant management because they did not meet the criteria for this. Follow-up could be a serious issue in an environment like ours, where people have poor health-seeking behavior.

Acute presentation with ruptured ectopic pregnancy and cardiovascular compromise from massive blood loss often result in life-threatening morbidity or mortality. For women who present in shock, immediate surgery after resuscitation is both diagnostic and therapeutic. ${ }^{31}$ This requires immediate resuscitation of such patients with intravenous fluid and blood, emergency laparotomy with salpingectomy, and conservation of the ovaries, as was done for the majority of our patients as life-saving measures. Laparoscopic surgery can be used both for diagnosis and treatment of unruptured ectopic pregnancy, provided there are no contraindications. However, the center lacked functional diagnostic and therapeutic laparoscopic equipment for this modality of management.

Salpingectomy was the commonest life-saving surgical procedure performed in the studied subjects, since most of the cases were ruptured ectopic pregnancies with massive hemoperitoneum. This management option was in line with the recommendations of the National Institute of Clinical Excellence that women with such presentation of ectopic gestation should have a salpingectomy. ${ }^{32}$ In developing countries like Nigeria, where the majority of patients present after rupture, emergency surgical interventions remain the mainstay of treatment, ${ }^{23,24}$ even though some scholars have recommended conservative surgeries for well-selected patients. ${ }^{30}$ Given the high risk of recurrence and the finding that $3.4 \%$ of our subjects had a history of previous ectopic 
pregnancy, women with a history of previous ectopic pregnancy should be followed up carefully, even in the absence of symptoms. ${ }^{31}$ The chance of intrauterine pregnancy in subsequent pregnancies is $40 \%$ after salpingectomy, $60 \%$ after conservative tubal surgery, and $87 \%$ after medical treatment. ${ }^{3}$ This study did not follow up patients for these outcomes, hence this could be an area for further research.

There was a significant degree of morbidity associated with ectopic pregnancy in this study, as shown by the results. This may be attributed to the delay in diagnosis and seeking treatment, and may have contributed to the slightly longer duration of hospitalization recorded. Anemia, which was the commonest complication in this study, was due to excessive blood loss from the rupture site, necessitating blood transfusion. Most patients were transfused with blood from the hospital blood bank services, while fewer patients had an auto-blood transfusion intraoperatively. Blood transfusions, especially those from donors, could increase the risk of acquiring blood-borne pathogens, such as HIV, hepatitis B and $\mathrm{C}$, and cytomegalovirus infections. These blood transfusions also placed an additional burden on the already-limited health resources in our center and the country, but were life-saving, with no reported case of any transfusion-related blood-borne infections. Patients with interstitial/cornual ectopic pregnancy may have a sevenfold-higher mortality due to the fact that they rupture later and bleed more. ${ }^{33,34}$ The casefatality rate of $1.4 \%$ recorded in this study was similar to the case-fatality rates published by numerous hospitals in Nigeria and other African countries, which ranged between $1 \%$ and $3 \%{ }^{26-28,35}$ The three deaths recorded resulted from massive blood loss from the rupture sites (interstitial/cornual). There is no doubt this also contributed to the country's high maternal mortality ratio (800-1,100 per 100,000 live births $)^{36}$ during the study period. Efforts to prevent deaths related to ectopic pregnancy must ensure early access to care, promote awareness about risk factors and early pregnancy testing, and raise public awareness about substance abuse, especially during pregnancy. ${ }^{37}$

\section{Conclusion and recommendations}

Since ectopic pregnancy remains a gynecological catastrophe in sub-Saharan African countries and a major challenge to the reproductive performance of women worldwide, it should be considered a relevant public health issue in Nigeria. With its rising incidence, which is likely to continue increasing because of the various factors discussed, it is necessary to devise means of early detection and treatment. This could be achieved by providing adequate materials, manpower, and equipment of health facilities, as well as a prompt and efficient referral system, good access roads, and efficient transportation, which will ensure early presentation in hospitals and prompt management of cases.

Health education on safer sex and provision of familyplanning services, such as condoms and other barrier contraceptives, will help prevent sexually transmitted infection and unwanted pregnancies, thereby reducing the incidence of pelvic infection and postabortal complications. These interventions are expected to reduce the incidence of ectopic pregnancy and the consequent loss of reproductive potential among Nigerian women, as has been recorded in some advanced countries of the world.

\section{Disclosure}

The authors report no conflicts of interest in this work.

\section{References}

1. Sara HG, Uzelac PS. Early pregnancy risks. In: DeCherney AH, Nathan L, Goodwin MT, Laufer N, editors. Current Diagnosis and Treatment: Obstetrics and Gynecology. 10th ed. Columbus $(\mathrm{OH})$ : McGraw-Hill; 2007:259-272.

2. Panti A, Ikechukwu NE, lukman OO, Yakubu A, Egondu SC, Tanko BA. Ectopic pregnancy at Usmanu Danfodiyo University Teaching Hospital Sokoto: a ten year review. Ann Niger Med. 2012;6(2):87-91.

3. Abdul FI. Ectopic pregnancy in Ilorin: a review of 278 cases. Niger $J$ Med. 2000;9(3):92-96.

4. Erickson BT. Ectopic pregnancy. In: Bader T, editor. Ob/Gyn Secrets. 3rd ed. Maryland Heights (MO): Mosby; 2007:109-113.

5. Gharoro EP, Igbafe AA. Ectopic pregnancy revisited in Benin City, Nigeria: analysis of 152 cases. Acta Obstet Gynecol Scand. 2002;81(12): $1139-1143$.

6. Monga A. Ectopic pregnancy. In: Monga A, Baker P, editors. Gynaecology by Ten Teachers. 18th ed. London: Hodder Education; 2006:97-99.

7. Mukul LV, Teal SB. Current management of ectopic pregnancy. Obstet Gynecol Clin North Am. 2007;34(3):403-419.

8. Otubu JAM, Pam IC. Ectopic pregnancy. In: Agboola A, editor. Textbook of Obstetrics and Gynaecology for Medical Students. 2nd ed. Ibadan, Nigeria: Heinemann; 2006:101-105.

9. Drife JS. Tubal pregnancy: rising incidence, earlier diagnosis, more conservative management. BMJ. 1990;301:1057-1058.

10. Ankum WM, Mol BW, Van der Veen F, Bossuyt PM. Risk factors in ectopic pregnancy. Fertil Steril. 1996;65(6):1093-1099.

11. Kim HH, Fox JH. The fallopian tube and ectopic pregnancy. In: Ryan KJ, Berkowitz RS, et al, editors. Kistner's Gynecology and Women's Health. New York: Mosby Inc; 1999:143-165.

12. Gant NF, Cunningham FG, editors. Ectopic pregnancy. In: Basic Gynecology and Obstetrics. Norwalk: Appleton \& Lange; 1993:60-69.

13. Confidential Enquiries into Maternal and Child Health. Why Mothers Die - 2000-2002: The Sixth Report of the Confidential Enquiries into Maternal Deaths in the United Kingdom, 2000-2002. London: RCOG press; 2004.

14. Jurkovic D. Ectopic pregnancy. In: Edmonds K, editor. Dewhurst's Textbook of Obstetrics and Gynaecology for Postgraduates. 7th ed. Oxford: Blackwell Science; 2007:106-116.

15. Sotubo O, Aboyeji AP. Ectopic pregnancy in Ilorin, Nigeria: a five-year review. Niger Med Pract. 1994;27(3):25-27.

16. Igberase GO, Ebeigbe PN, Igbeboji OF, Ajupo BI. Ectopic pregnancy: an 11-year review in a tertiary center in the Niger Delta. Trop Doct. 2005;35(3):175-177. 
17. Anorlu RI, Oluwole A, Abudu OO, Adebanjo S. Risk factors for ectopic pregnancy in Lagos, Nigeria. Acta Obstet Gynecol Scand. 2005;84(2): $184-188$.

18. Ikeme AC, Ezegwui HU. Morbidity and mortality following tubal ectopic pregnancies in Enugu, Nigeria. J Obstet Gynaecol. 2005;25(6): 596-598.

19. Olatunji AD, Abudu OO. A review of maternal mortality in Lagos University Teaching Hospital. Niger Med Pract. 1996;31(1):12-16.

20. Makinde OO, Ogunniyi SO. Ectopic pregnancy in Ile-Ife, Nigeria: analysis of 203 cases. Niger Med J. 1990;20:23-25.

21. Ilesanmi AO, Sobwale OA. Ectopic pregnancy in Ibadan, Nigeria. Nigeria Med J. 1992;23(1):11-14.

22. Spiff AI, Inimgba NM, Jamabo RS. Ruptured heterotopic pregnancy: a case report and brief review of the literature. Niger J Med. 2005;14(3): 315-316.

23. Stabile I, Grundzinskas JG. Ectopic pregnancy: a review of incidence, aetiology and diagnostic aspects. Obstet Gynecol Surv. 1990;45(6): 335-347.

24. Aneziokoro EA, Dimejesi BI. Ectopic pregnancy in Abakaliki, Eastern Nigeria. Ebonyi Med J. 2003;2(2):39-43.

25. Oronsaye AU, Odiase GI. Incidence of ectopic pregnancy in Benin City, Nigeria. Trop Doct. 1981;11(4):160-163.

26. Ola ER, Imosemi DO, Egwuatu JI, Abudu OO. Ectopic pregnancy: Lagos University Teaching Hospital experience over a five-year period. Niger Q J Hosp Med. 1999;9(2):100-103.

27. Ekele BA. Medical treatment of ectopic pregnancy using parenteral methotrexate. West Afr J Med. 2001;20(3):181-183.

28. Baffoe S, Nkyekyer K. Ectopic pregnancy in Korle Bu Teaching Hospital, Ghana: a three-year review. Trop Doct. 1999;29(1):18-22.
29. Sivalingam VN, Duncan WC, Kirk E, Shephard LA, Horne AW. Diagnosis and management of ectopic pregnancy. J Fam Plann Reprod Health Care. 2011;37(4):231-240.

30. Kurt TB. Ectopic pregnancy. N Engl J Med. 2009;361:369-387.

31. Practice Committee of the American Society of Reproductive Medicine. Medical treatment of ectopic pregnancy. Fertil Steril. 2008; 90(Suppl 5):S206-S212.

32. National Institute for Health and Care Excellence. Ectopic pregnancy and miscarriage. 2012. Available from: http://guidance.nice.org.uk/ cg154. Accessed July 17, 2013.

33. Speroff L, Glass RH, Kase NG. Clinical Gynecological Endocrinology and Infertility. 6th ed. Philadelphia: Lippincott Williams \& Wilkins; 1999.

34. Shaw JL, Dey SK, Critchley HO, Horne AW. Current knowledge of the aetiology of human tubal ectopic pregnancy. Hum Reprod Update. 2010;16(4):432-444.

35. Ezegwui HU, Onoh RC, Ikeako LC, et al. Investigating maternal mortality in a public teaching hospital, Abakaliki, Ebonyi State, Nigeria. Ann Med Health Sci Res. 2013;3(1):75-80.

36. Rogo KO, Oucho J, Mwalali P. Maternal mortality. In: Jamison DT, Feachem RG, Makgoba MW, et al, editors. Disease and Mortality in Sub-Saharan Africa. 2nd ed. Washington DC: World Bank; 2006. Available from: http://www.ncbi.nlm.nih.gov/books/NBK2279/. Accessed August 5, 2013.

37. Centers for Disease Control and Prevention. Ectopic pregnancy mortality - Florida, 2009-2010. MMWR Morb Mortal Wkly Rep. 2012; 61(6):106-109.
International Journal of Women's Health

\section{Publish your work in this journal}

The International Journal of Women's Health is an international, peerreviewed open-access journal publishing original research, reports, editorials, reviews and commentaries on all aspects of women's healthcare including gynecology, obstetrics, and breast cancer. The manuscript management system is completely online and includes

\section{Dovepress}

a very quick and fair peer-review system, which is all easy to use. Visit http://www.dovepress.com/testimonials.php to read real quotes from published authors. 